\title{
Steroid Retrial After Rituximab and Mycophenolate Mofetil in Pediatric Refractory Nephrotic Syndrome
}

\author{
Amrit Kirpalani ${ }^{\mathrm{a}}$, Guido Filler ${ }^{\mathrm{b}}$, Joanne Grimmer ${ }^{\mathrm{c}}$, Vladimir Belostosky ${ }^{\mathrm{d}}$, \\ Steven Arorad, Ajay P. Sharma ${ }^{c, e}$
}

\begin{abstract}
Steroid-resistant nephrotic syndrome (SRNS) is a challenging condition. In pediatric SRNS, cyclosporine is the first-line treatment choice, with approximately $60 \%$ success rate. In cyclosporine-resistant disease, treatment modalities such as cyclophosphamide, mycophenolate mofetil (MMF), tacrolimus, vincristine, galactose, plasmapheresis and rituximab have been tried with variable success. In this paper, we report a patient with SRNS who remained resistant to all the above stated medications except a moderate response to rituximab. After rituximab, MMF re-initiation did not induce further improvement. Prednisone retrial thereafter induced a prompt remission. The significance of this finding in context with current literature has been discussed.
\end{abstract}

Keywords: Focal segmental glomerulosclerosis; Refractory nephrotic syndrome; Rituximab; Mycophenolate mofetil; Steroid retrial

\section{Introduction}

Steroid-resistant nephrotic syndrome (SRNS) is a challenging medical condition. In children with SRNS, cyclosporine is considered to be the first-line treatment option [1-3]. However, the treatment algorithm is less defined in those who do not respond to cyclosporine. Mycophenolate mofetil (MMF)

\footnotetext{
Manuscript accepted for publication May 06, 2016

aDepartment of Pediatrics, Western University, Children's Hospital, London Health Sciences Centre, London, Ontario, Canada

bDivision of Nephrology, Departments of Pediatrics, Medicine, and Pathology and Laboratory Medicine, Western University, Children's Hospital, London Health Sciences Centre, London, Ontario, Canada

'Division of Nephrology, Department of Pediatrics, Western University, Children's Hospital, London Health Sciences Centre, London, Ontario, Canada

dDivision of Nephrology, Department of Pediatrics, McMaster University, McMaster Children's Hospital, Hamilton, Ontario, Canada

${ }^{e}$ Corresponding Author: Ajay Sharma, Pediatric Nephrology, Department of Pediatrics; Western University, Schulich School of Medicine and Dentistry; Children's Hospital, London Health Sciences Centre; 800, Commissioners Road East; London, Ontario, N6P1W2, Canada.

Email: ajay.sharma@lhsc.on.ca
}

doi: http://dx.doi.org/10.14740/wjnu267w
[4], plasmapheresis [5], vincristine [6], Mendoza protocol (combination of high dose steroid and cyclophosphamide) [7], tacrolimus [8] and galactose [9] have shown some value in cyclosporine-resistant SRNS. Recently, rituximab has been found to be another useful option in SRNS although with variable success $[10,11]$. The absence of response to any of these medications makes the management of SRNS extremely challenging due to the lack of further treatment options and the likelihood of progressive chronic kidney disease.

In this paper, we report a patient with cyclosporine-resistant SRNS, who did not respond to above stated medications and the response to rituximab was moderate. Subsequent retrial of prednisone however induced a complete remission.

\section{Case Report}

\section{Initial clinical presentation and diagnosis}

The 2-year-old Caucasian boy initially presented in the year 2007 with generalized edema, nephrotic-range proteinuria, hypoalbuminemia $(<25 \mathrm{~g} / \mathrm{L})$ and hypercholesterolemia, consistent with the diagnosis of nephrotic syndrome. The evaluation for an underlying primary disease was unremarkable, including normal serum complement $\mathrm{C} 3$ and $\mathrm{C} 4$ levels. Prednisolone given at a dose of $60 \mathrm{mg} / \mathrm{m}^{2}$ per day did not induce remission in 6 weeks. A kidney biopsy confirmed underlying focal segmental glomerulosclerosis (FSGS). Given the diagnosis of FSGS, genetic testing showed no disease-causing mutations in NPHS2 (podocin), ACTN4 (alpha-actinin-4), TRPC6 (transient receptor potential cation channel 6), CD2AP (CD2-associated protein) or NPHS1 (nephrin).

Earlier he was diagnosed with type 1 diabetes at 11 months of age and hypothyroidism in the second year of life. Further evaluation in view of these diagnoses did not reveal hearing impairment, autoimmune thyroiditis or another endocrinopathy. The parents did not have diabetes, thyroid, kidney or an autoimmune disorder.

\section{Initial cyclosporine-responsive course}

With no response to steroid, cyclosporine was administered at a dose of $150 \mathrm{mg} / \mathrm{m}^{2}$ per day in two divided doses and pred- 


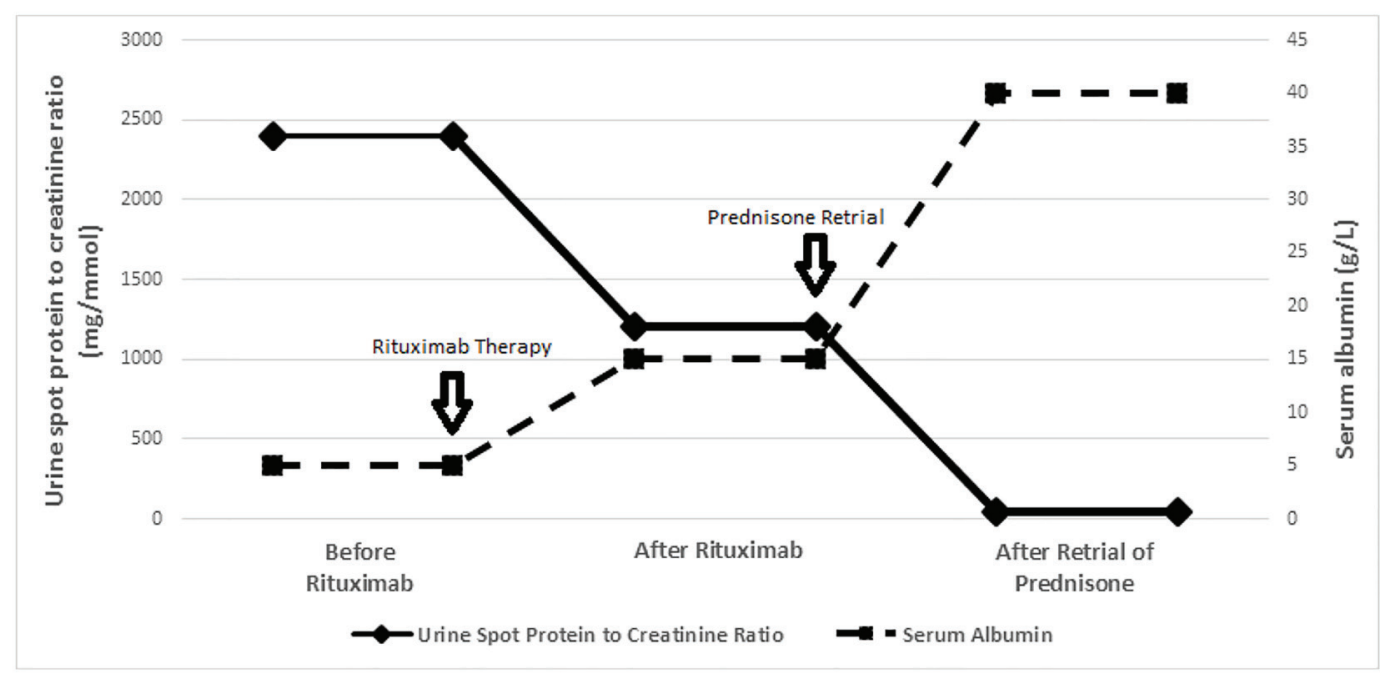

Figure 1. Trend of proteinuria (urine spot protein to creatinine ratio) and serum albumin levels (before rituximab, after rituximab and after prednisone retrial). Before rituximab: proteinuria and serum albumin levels prior to rituximab. After rituximab: plateau levels of proteinuria and serum albumin after rituximab. After prednisone retrial: plateau levels of proteinuria and serum albumin level after prednisone.

nisolone at a dose of $0.5 \mathrm{mg} / \mathrm{kg}$ per day. On cyclosporine, he attained remission. While on stable cyclosporine dose (trough level 150 - $250 \mathrm{ng} / \mathrm{mL}$ ), there were five relapses, which responded favorably to prednisone (May 2009, December 2009, December 2010, January 2011 and July 2011). The first relapse was complicated by sepsis and acute kidney injury, requiring short-term hemodialysis.

\section{Later cyclosporine-resistant course}

While on cyclosporine, the patient relapsed again in October 2011 with no response to prednisone. Over time, the edema became significantly worse such that he required multiple diuretics and 25\% albumin infusions regularly 3 - 4 times a week. In view of persistent relapse despite adequate cyclosporine exposure (trough level 150 - $250 \mathrm{ng} / \mathrm{mL}$ ), cyclosporine was discontinued and the following medications were tried.

\section{Vincristine}

In December 2011, four intravenous vincristine doses, $1.5 \mathrm{mg} /$ $\mathrm{m}^{2}$ each, followed by the fifth dose a month after the fourth dose were administered with no response [9].

\section{Mendoza protocol (intravenous methylprednisolone and cyclophosphamide)}

In February 2012, intravenous methylprednisolone (MP) infusions at a dose of $30 \mathrm{mg} / \mathrm{kg}$ weekly for 12 weeks along with cyclophosphamide ( $2 \mathrm{mg} / \mathrm{kg} /$ day) for 8 weeks were administered [7]. While on MP for 2 weeks, oral prednisone was started at a dose of $2 \mathrm{mg} / \mathrm{kg}$ every other day for 10 weeks [7].
On this regimen, there was a transient improvement in serum albumin to $34 \mathrm{~g} / \mathrm{L}$ for a week followed by the drop to the baseline of $<10 \mathrm{~g} / \mathrm{L}$.

\section{Tacrolimus and MMF}

The patient received a combination of tacrolimus $0.15 \mathrm{mg} /$ $\mathrm{kg} /$ day in two divided doses (trough level $6-10 \mu \mathrm{g} / \mathrm{L}$ ), MMF $600 \mathrm{mg} / \mathrm{m}^{2}$ per dose twice daily (trough mycophenolic acidMPA level 3 - $5 \mathrm{mg} / \mathrm{L}$ ) and prednisone $0.5 \mathrm{mg} / \mathrm{kg}$ daily for 6 months, with no change in proteinuria and edema control measures.

\section{Galactose}

Oral galactose $(0.2 \mathrm{~g} / \mathrm{kg} /$ dose twice daily) was administered for 16 weeks, with no response [9].

\section{Plasma exchange}

In April to May 2013, six sessions of plasmapheresis were performed in a dose of one and a half plasma volume replacement by $5 \%$ albumin [5], with no response.

\section{Rituximab}

Between May and July 2013, the patient received four rituximab infusions at a dose of $375 \mathrm{mg} / \mathrm{m}^{2}$ each $[10,11]$, resulting in B-cell depletion (CD19<1\%). Following rituximab, his urinary protein to creatinine ratio decreased from $2,200-2,400$ $\mathrm{mg} / \mathrm{mmol}$ to $1,100-1,300 \mathrm{mg} / \mathrm{mmol}$ and serum albumin in- 
creased from $<10 \mathrm{~g} / \mathrm{L}$ to $15-17 \mathrm{~g} / \mathrm{L}$ (Fig. 1); the requirement of multiple diuretics continued although the frequency of $25 \%$ albumin infusions became intermittent.

\section{MMF retrial}

Based on previous reports suggesting the benefit of MMF in maintaining remission after a complete response to rituximab $[12,13]$, MMF was restarted in January 2014, 6 months after rituximab, at a dose of $600 \mathrm{mg} / \mathrm{m}^{2}$ per dose twice daily (trough MPA target level 3 - $5 \mathrm{mg} / \mathrm{L}$ ). On MMF for the next 6 months, no further improvement in proteinuria and serum albumin level was noted.

\section{Steroid retrial}

Based on the reported benefit of prednisone retrial after rituximab in two patients $[14,15]$, in August 2014 a year after rituximab and 6 months of MMF, oral prednisone was re-initiated in the dose of $60 \mathrm{mg} / \mathrm{m}^{2}$ daily. Within 2 weeks of prednisone start, urine protein to creatinine ratio decreased from 1,100 - 1,300 $\mathrm{mg} / \mathrm{mmol}$ to $30-50 \mathrm{mg} / \mathrm{mmol}$ and serum albumin increased from $14-16 \mathrm{~g} / \mathrm{L}$ to $39-41 \mathrm{~g} / \mathrm{L}$ (Fig. 1); edema resolved and diuretics were discontinued. Prednisone was administered at $60 \mathrm{mg} / \mathrm{m}^{2}$ daily for 6 weeks, $40 \mathrm{mg} / \mathrm{m}^{2}$ every other day for 6 weeks, followed by a slow wean to $10 \mathrm{mg}$ daily.

\section{Follow-up}

When last seen in March 2016, the patient had maintained a remission for more than a year on MMF $600 \mathrm{mg} / \mathrm{m}^{2}$ per dose twice daily (trough MPA target level 3 - $5 \mathrm{mg} / \mathrm{L}$ ) and prednisone $10 \mathrm{mg}$ daily. He remained normotensive and his estimated glomerular filtration rate was $124 \mathrm{~mL} / \mathrm{min} / 1.73 \mathrm{~m}^{2}$. During follow-up, he did not develop any major infection or other adverse effect except exaggerated appetite and challenges in diabetic control while on high-dose prednisone.

\section{Discussion}

The response to prednisone retrial in our patient, manifested by the resolution of proteinuria, normalization of serum albumin and discontinuation of diuretics within 2 weeks of prednisone initiation, suggested that rituximab and MMF can induce steroid sensitivity despite previous SRNS and multi-drug resistance.

The response to prednisone retrial in our patient was clinically significant considering a high risk of future chronic kidney disease in refractory SRNS and significant complications of unremitting nephrotic syndrome. There is limited evidence in literature to support the effectiveness of rituximab in inducing steroid sensitivity in refractory SRNS. A synergy between rituximab and steroid was suggested by a response to rituximab in eight of the 10 patients with refractory SRNS when rituximab was combined with methylprednisolone [16]. To add up to this observation, two children with refractory SRNS responded to prednisone when prednisone was retried shortly after a failed response to rituximab $[14,15]$.

The strength of our finding was an adequate time gap between various interventions to differentiate the effectiveness of individual treatments. Rituximab was separated from previous immunosuppression by a year. Prednisone retrial was separated from rituximab by a year and from MMF by 6 months, suggesting against a delayed effect of rituximab and MMF while interpreting the effectiveness of prednisone retrial. A diseasemitigating effect of rituximab in our patient was suggested by a moderate clinical response to it, in association with rituximabinduced B-cell suppression. In absence of a clinical response to MMF re-initiation, its additive benefit to rituximab remains speculative; however, it remains a possibility considering targeting of B cells by both rituximab and MMF and previous reports suggesting lesser relapses with MMF use in complete responders to rituximab $[12,13]$.

We conclude that prednisone can be a potential treatment option in refractory SRNS when retried after rituximab. An additive role of MMF in this context needs further evaluation. Larger studies are needed to establish the benefit of prednisone retrial in refractory SRNS and to assess the adverse effect profile of this treatment approach.

\section{Funding Source}

None.

\section{Conflicts of Interest}

None.

\section{Abbreviations}

FSGS: focal segmental glomerulosclerosis; MMF: mycophenolate mofetil; MP: methylprednisolone; SRNS: steroid-resistant nephrotic syndrome

\section{References}

1. Kidney Disease Improving Global Outcomes (KDIGO) Glomerulonephritis Work Group. KDIGO Clinical Practice Guideline for Glomerulonephritis. Kidney Inter Suppl. 2012;2:139-274.

2. Lieberman KV, Tejani A. A randomized double-blind placebo-controlled trial of cyclosporine in steroid-resistant idiopathic focal segmental glomerulosclerosis in children. J Am Soc Nephrol. 1996;7(1):56-63.

3. Lombel RM, Hodson EM, Gipson DS. Treatment of steroid-resistant nephrotic syndrome in children: new guidelines from KDIGO. Pediatr Nephrol. 2013;28(3):409414. 
4. Gipson DS, Trachtman H, Kaskel FJ, Greene TH, Radeva MK, Gassman JJ, Moxey-Mims MM, et al. Clinical trial of focal segmental glomerulosclerosis in children and young adults. Kidney Int. 2011;80(8):868-878.

5. Mitwalli AH. Adding plasmapheresis to corticosteroids and alkylating agents: does it benefit patients with focal segmental glomerulosclerosis? Nephrol Dial Transplant. 1998;13(6):1524-1528.

6. Almeida MP, Almeida HA, Rosa FC. Vincristine in steroid-resistant nephrotic syndrome. Pediatr Nephrol. 1994;8(1):79-80.

7. Mendoza SA, Reznik VM, Griswold WR, Krensky AM, Yorgin PD, Tune BM. Treatment of steroid-resistant focal segmental glomerulosclerosis with pulse methylprednisolone and alkylating agents. Pediatr Nephrol. 1990;4(4):303-307.

8. Straatmann C, Ayoob R, Gbadegesin R, Gibson K, Rheault MN, Srivastava T, Tran CL, et al. Treatment outcome of late steroid-resistant nephrotic syndrome: a study by the Midwest Pediatric Nephrology Consortium. Pediatr Nephrol. 2013;28(8):1235-1241.

9. Sgambat K, Banks M, Moudgil A. Effect of galactose on glomerular permeability and proteinuria in steroid-resistant nephrotic syndrome. Pediatr Nephrol. 2013;28(11):2131-2135.

10. Magnasco A, Ravani P, Edefonti A, Murer L, Ghio L, Be- lingheri M, Benetti E, et al. Rituximab in children with resistant idiopathic nephrotic syndrome. J Am Soc Nephrol. 2012;23(6):1117-1124.

11. Prytula A, Iijima K, Kamei K, Geary D, Gottlich E, Majeed A, Taylor M, et al. Rituximab in refractory nephrotic syndrome. Pediatr Nephrol. 2010;25(3):461-468.

12. Ito S, Kamei K, Ogura M, Sato M, Fujimaru T, Ishikawa T, Udagawa T, et al. Maintenance therapy with mycophenolate mofetil after rituximab in pediatric patients with steroid-dependent nephrotic syndrome. Pediatr Nephrol. 2011;26(10):1823-1828.

13. Sharma AP, Filler G. Role of mycophenolate mofetil in remission maintenance after a successful response to rituximab. Pediatr Nephrol. 2009;24(2):423-424.

14. Fujinaga S, Hara T. Re-treatment with high-dose prednisolone after rituximab infusion for childhood-onset steroid-resistant nephrotic syndrome. Pediatr Nephrol. 2014;29(7):1291-1292.

15. Hirano D, Fujinaga S, Nishizaki N. The uncertainty of rituximab and steroid dosing in refractory steroid-resistant nephrotic syndrome. Clin Nephrol. 2012;77(6):510-512.

16. Kamei K, Okada M, Sato M, Fujimaru T, Ogura M, Nakayama M, Kaito H, et al. Rituximab treatment combined with methylprednisolone pulse therapy and immunosuppressants for childhood steroid-resistant nephrotic syndrome. Pediatr Nephrol. 2014;29(7):1181-1187. 